\title{
EFEKTIVITAS PERTUMBUHAN BENIH IKAN SUMATERA (Puntius tetrazona) MELALUI PENDEKATAN KETINGGIAN AIR MEDIA PEMELIHARAAN
}

\section{Growth effectiveness of Tiger Barb seeds (Puntius tetrazona) through maintenance media water levels approach}

\author{
Wahyu Noor Yuliansyah ${ }^{1}$, Sumantriyadi ${ }^{2}$, Syaeful Anwar ${ }^{2}$, Rahma Mulyani $^{2}$ \\ 1) Program Studi Ilmu Perikanan Fakultas Perikanan dan Kelautan UPGRI Palembang \\ 2) Program Studi Budi Daya Ikan Fakultas Perikanan dan Kelautan Universitas PGRI Palembang \\ *Corresponding author: sumantriyadi5@gmail.com
}

\begin{abstract}
ABSTRAK
Ketinggian air berperan penting untuk pertumbuhan dan kelangsungan hidup benih ikan Sumatera (Puntius tetrazona) hal ini dikarenakan semakin besar jarak yang ditempuh untuk mengambil oksigen ke permukaan maka semakin besar energi yang terpakai sehingga akan berpengaruh terhadap pertumbuhan benih ikan Sumatera (Puntius tetrazona). Dari informasi di atas, perlu dilakukan penelitian tentang pertumbuhan dan kelangsungan hidup benih ikan Sumatera (Puntius tetrazona) dengan ketinggian air yang berbeda. Penelitian ini dilaksanakan selama 30 hari pada Bulan Juli-Agustus 2018 bertempat di Unit Balai Benih Ikan Kota Palembang. Penelitian ini menggunakan Metode Eksperimen dengan Rancangan Acak Lengkap (RAL) dengan 3 (tiga) taraf perlakuan, masing-masing perlakuan dilakukan 3 (tiga) kali ulangan, yaitu P1 (ketinggian air 5cm), P2 (ketinggian air 10cm), dan P3 (ketinggian air $15 \mathrm{~cm})$. Sampling dilakukan pada awal, pertengahan dan akhir penelitian. Hasil penelitian menunjukkan bahwa P2 (ketinggian air $10 \mathrm{~cm}$ ) memberikan hasil terbaik yaitu pertambahan berat sebesar 0.88 gram dan panjang sepanjang $3.39 \mathrm{~cm}$ serta dan kelangsungan Hidup sebesar $100 \%$.
\end{abstract}

Kata Kunci : Ikan Sumatera, pertumbuhan, kelangsungan hidup

\section{ABSTRACT}

The water level plays an important role for the growth and survival of tigerbarb seeds (Puntius tetrazona) because the greater the distance taken to take oxygen to the surface, the greater the energy used so that it will affect the growth of tigerbarb seeds (Puntius tetrazona). From the information above, it is necessary to do research on the growth and survival of tigerbarb seeds (Puntius tetrazona) with different water levels. This research was carried out for 30 days in July-August 2018 at the Unit of Fish Seed Center of the City of Palembang. This study used the Experimental Method with Completely Randomized Design (CRD) with 3 (three) levels of treatment, each treatment was carried out 3 (three) replications, namely P1 (Water Level $5 \mathrm{~cm}$ ), P2 (Water Height 10cm), and P3 (15cm water level). Sampling was carried out at the beginning, middle and end of the study. The results showed that $P 2(10 \mathrm{~cm}$ water level) gave the best results, namely weight gain of 0.88 grams and length of $3.39 \mathrm{~cm}$ and survival rate of $100 \%$.

Keywords: Tigerbarb, growth rate, survival rate

\section{PENDAHULUAN}

Indonesia merupakan negara yang mempunyai potensi besar sebagai penghasil ikan hias. Perairan tawar, payau, danau, dan laut Indonesia banyak dihuni oleh ikan hias dan ikan lainnya. Ikan 
Sumatera (Puntius tetrazona) mempunyai bentuk dan warna yang sangat menarik menyebabkan ikan Sumatera ini diminati penggemar ikan hias. Nilai estetis yang dihasilkan tergantung pada jenis ikan, warna, ukuran dan bentuk tubuh ikan (Nafsihi, 2016).

Ikan Sumatera (Puntius tetrazona) merupakan ikan dari genus puntius yang ditemukan di Pulau Sumatera dan Kalimantan (Indonesia), Malaysia dan Kamboja. Ikan Sumatera (Puntius tetrazona) mempunyai bentuk dan warna yang sangat menarik menyebabkan ikan Sumatera ini diminati penggemar ikan hias. Ikan ini menduduki peringkat ke 10 dengan jumlah individu yang diimpor pada tahun 2009 sebanyak 2,6 juta ekor (Makri, 2015).

Kebutuhan ikan Sumatera (Puntius tetrazona) di pasar sangat besar karena banyaknya permintaan dari distributor ikan hias maupun konsumen. Harga benih ikan Sumatera (Puntius tetrazona) berkisar Rp 350 - Rp 500 sedangkan harga induk ikan sumatera (Puntius tetrazona) berkisar $\mathrm{Rp}$ 10.000 - Rp 20.000 per ekor (Yuliansyah, 2017). Padat tebar yang optimum dan efisien dari segi biaya untuk produksi benih ikan Sumatera (Puntius tetrazona) sebaiknya diterapkan teknologi pemeliharaan yang intensif sehingga mencapai target yang diinginkan. Teknik yang tepat untuk memelihara ikan Sumatera dalam jumlah yang besar sudah seharusnya dilakukan agar tingkat kematiannya dapat ditekan, dengan melakukan manipulasi lingkungan yang sesuai habitat aslinya (Sari et al, 2014).

Menurut Samaun, dkk., (2015), pengaruh ketinggian air yang berbeda terhadap pertumbuhan dan kelangsungan hidup benih ikan lele sangkuriang dengan panjang awal $\pm 5,0 \mathrm{~cm}$ menyatakan ketinggian air yang tinggi menyebabkan jarak ke permukaan semakin besar sehingga mempengaruhi aktivitas ikan lele dalam mengambil oksigen langsung ke udara. Semakin besar jarak yang ditempuh untuk mengambil oksigen ke permukaan semakin besar pula energi yang terpakai sehingga akan berpengaruh terhadap pertumbuhan ikan.

Pemeliharaan benih ikan Sumatera dengan ketinggian air tertentu masih terbatas informasinya. Dari informasi di atas, perlu dilakukan kembali penelitian pembanding tentang ketinggian air pada ikan Sumatera. Sementara itu belum diketahui secara jelas tentang ketinggian air yang baik untuk pertumbuhan benih ikan Sumatera. Mengingat perlu adanya sebuah informasi tentang ketinggian air yang baik untuk pertumbuhan ikan Sumatera tersebut.

\section{METODOLOGI}

\section{Waktu dan tempat}

Penelitian ini dilaksanakan pada bulan Juli - Agustus 2018, di Balai Benih Ikan Kota Palembang dan Uji Kualitas Air dilakukan di Laboratorium Kesehatan Lingkungan dan Hama Penyakit Palembang.

\section{Ikan Uji}

Ikan uji yang digunakan dalam penelitian ini adalah benih ikan Sumatera (Puntius tetrazona) ukuran $2,5-3 \mathrm{~cm}$ sebanyak 540 ekor, dengan masing-masing aquarium berisi padat tebar yang berbeda mengikuti ketinggian air, padat penebaran 5 ekor/l (Thabrani, 2015) dalam (Rafiansyah, 2017). Benih diperoleh dari Balai Penelitian dan Pengembangan Budidaya Ikan Hias Depok hal ini dikarenakan kualitas benih lebih terjamin.

\section{Wadah Biota Uji}

Alat yang digunakan berupa akuarium kaca berukuran 40 × 30 × $30 \mathrm{~cm}$ dengan perlakuan ketinggian air yaitu $5 \mathrm{~cm}$, $10 \mathrm{~cm}$ dan $15 \mathrm{~cm}$. Ukuran akuarium tersebut sesuai dalam penelitian (Sari et al, 2014) yang menggunakan akuarium berukuran $40 \times 30 \times 30 \mathrm{~cm}$ dan berasal dari Balai Benih Ikan Gandus Palembang. Persiapan pertama adalah sebelum digunakan aquarium dicuci bersih dan dikeringkan selama 1 (satu) hari tergantung 
kondisi cuaca hal ini bertujuan untuk mensterilkan wadah dari hama dan penyakit yang tersisa. Penelitian ini menggunakan aquarium berukuran $40 \times 30$ x $30 \mathrm{~cm}$ sebanyak 9 buah dengan ketinggian air yang berbeda kemudian diisi air sesuai dengan perlakuan masing-masing dan beri aerasi dengan tekanan kecil guna untuk mensuplai oksigen (Sari et al, 2014).

\section{Rancangan Percobaan}

Metode Penelitian ini bersifat percobaan atau eksperimen (Sari et al, 2014). Rancangan yang digunakan pada penelitian ini adalah Rancangan Acak Lengkap (RAL) non faktorial (Sari et al, 2014) dengan 3 (tiga) taraf perlakuan dan 3 (tiga) kali ulangan. Menurut Sari et al, (2014) perlakuan dalam penelitian adalah memelihara benih ikan sumatera pada ketinggian air yang berbeda yang dibagi dengan 3 perlakuan yaitu perlakuan P1 ketinggian Air $5 \mathrm{~cm}$, Perlakuan P2 ketinggian Air $10 \mathrm{~cm}$ dan perlakuan P3 ketinggian Air $15 \mathrm{~cm}$.

\section{Prosedur Penelitian}

Padat penebaran ikan mengikuti ketinggian air yaitu untuk ketinggian air (5 $\mathrm{cm})$ dengan padat penebaran 30 ekor, ketinggian air $(10 \mathrm{~cm})$ dengan padat penebaran 60 ekor dan ketinggian air (15 $\mathrm{cm})$ dengan padat penebaran sebanyak 90 ekor. Penebaran ikan uji bisa dilakukan pada sore hari sewaktu sinar matahari rendah, sebelum benih dilepas dilakukan adaptasi suhu selama sekitar 5 menit. Hal ini dilakukan untuk mengurangi stres pada ikan Sumatera (Puntius tetrazona) sebelum benih ikan ditebar dalam akuarium terlebih dahulu dilakukan aklimatisasi pada benih ikan Sumatera (Puntius tetrazona). Aklimatisasi dilakukan dengan cara memasukkan wadah yang berisi benih dengan posisi wadah dimiringkan secara perlahan sehingga benih akan keluar sendirinya ke dalam akuarium (Sari et al, 2014).
Pemeliharaan dilakukan dalam aquarium selama 30 hari. Selama pemeliharaan benih ikan Sumatera (Puntius tetrazona) diberi makan pakan alami berupa cacing darah dengan frekuensi pemberian sebanyak tiga kali dalam satu hari secara At satiation yaitu pukul 08.00, 12.00, dan 16.00 WIB. Hal ini sesuai dalam pernyataan Nafsihi (2016) yaitu frekuensi pemberian pakan pada benih ikan adalah tiga kali dalam sehari.

Pengamatan

pertumbuhan dilakukan 3 kali selama penelitian yaitu awal, pertengahan dan akhir penelitian. Pengamatan dilakukan dengan cara sampling, larva yang diambil sebanyak $30 \%$ dari jumlah total setiap akuarium untuk semua perlakuan (Armansyah, 2010). Parameter yang akan diukur untuk mengetahui pertumbuhan yaitu pengukuran bobot dan panjang. Untuk memudahkan proses pengukuran bobot dan panjang dapat digunakan air es, dimana air es ini berfungsi untuk alat bius sehingga benih tidak stress saat dilakukan pengukuran. Hal ini sesuai dengan pernyataan dalam penelitian Sari et al.,(2014) yaitu untuk memudahkan proses sampling maka diperlukan cairan bius atau sejenisnya untuk pemingsanan agar ikan tidak mengalami stress.

Selama pemeliharaan ikan, air yang digunakan akan kotor oleh sisa pakan dan kotoran ikan, maka dari itu perlu dilakukan penyiponan untuk membuang sisa - sisa kotoran yang mengendap didasar akuarium Pergantian air dilakukan sebanyak $30 \%$ untuk semua perlakuan, pergantian air dilakukan 2 hari sekali, hal ini dilakukan agar kualitas air tetap terjaga (Sari et al, 2014).

Pengelolaan kualitas air dilakukan dengan beberapa cara yaitu penyiponan yang dilakukan satu kali sehari, yakni pagi hari jam 9.00 WIB. Pergantian air yang dilakukan sebanyak 30\% untuk semua perlakuan, pergantian air dilakukan agar kualitas air tetap terjaga. Selain itu pengelolaan kualitas air juga dilakukan 
pengukuran kualitas air yang meliputi pengukuran suhu dan $\mathrm{pH}$, setiap hari,sedangkan amoniak, DO, dan nitrit dilakukan diakhir penelitan (Sari et al, 2014).

\section{Parameter yang Diamati \\ Pertumbuhan}

Pertumbuhan diamati dengan mengukur panjang dan bobot ikan. Data diperoleh dengan melakukan pengamatan 3 kali selama penelitian yaitu awal, pertengahan dan akhir penelitian dalam waktu 30 hari, setiap pengamatan benih diambil sebanyak 30\% dari jumlah ikan di akuarium. Pengamatan pertumbuhan berat dan panjang adalah sebagai berikut.

\section{Pertambahan Berat Mutlak}

Pengamatan pertambahan berat ikan dilakukan setiap 3 kali selama penelitian yaitu awal, pertengahan dan akhir penelitian dengan menggunakan rumus yang dikemukakan oleh Effendie (1997) sebagai berikut:

\section{$\mathbf{W m}=\mathbf{W t}-\mathbf{W o}$}

Keterangan :

$\mathrm{Wm}=$ Pertambahan bobot rata - rata (gram).

$\mathrm{Wt}=$ Bobot rata - rata akhir (gram).

Wo = Bobot rata - rata awal (gram).

\section{Pertambahan Panjang Mutlak}

Pengamatan pertambahan panjang ikan dilakukan setiap 3 kali selama penelitian yaitu awal, pertengahan dan akhir penelitian dengan menggunakan rumus yang dikemukakan oleh Effendie (1997) sebagai berikut:

\section{$\mathbf{P m}=\mathbf{P t}-\mathbf{P o}$}

Keterangan :

$\mathrm{Pm} \quad=$ Pertambahan panjang ikan $(\mathrm{cm})$.

$\mathrm{Pt} \quad=$ Panjang akhir ikan $(\mathrm{cm})$.

Po = Panjang awal ikan $(\mathrm{cm})$.
Kelangsungan Hidup (SR)

Pengamatan kelangsungan hidup ikan dilakukan dengan cara mengamati jumlah ikan yang masih hidup pada tiap bak setiap hari. Menurut Effendie (1997) tingkat kelangsungan hidup ikan dapat dihitung dengan rumus sebagai berikut :

$\mathrm{SR}=\frac{\mathrm{Nt}}{\mathrm{No}} x 100 \%$

Keterangan :

SR = Tingkat kelangsungan hidup (\%)

$\mathrm{Nt}=$ Jumlah ikan uji pada akhir

penelitian (ekor)

No = Jumlah ikan uji pada awal penelitian (ekor)

\section{Analisis Data}

Mengacu pada Hanafiah (2016). Data hasil penelitian dianalisis dengan menggunakan analisis sidik ragam (ANSIRA) untuk mengetahui pengaruh perlakuan yang diberikan terhadap pertumbuhan dan kelangsungan hidup larva Ikan Sumatera (Puntius tetrazona). Jika dari analisa sidik ragam diketahui bahwa perlakuan yang berbeda menunjukkan pengaruh yang berbeda nyata atau sangat nyata akan diuji lanjut. Untuk nilai KK (Koefisien Keragaman) 1-5 \% maka diuji lanjut dengan mengunakan BNJ (Beda Nyata Jujur), bila nilai KK 5-10 \% maka diuji lanjut dengan mengunakan BNT (Beda Nyata Terkecil) dan apabila nilai KK $>10 \%$ maka akan diuji lanjut dengan menggunakan Duncan. Sedangkan kualitas air akan dianalisis secara deskritif.

\section{HASIL DAN PEMBAHASAN Pertambahan Berat ikan Sumatera} (Puntius tetrazona)

Hasil pengamatan terhadap pertambahan berat rata-rata benih ikan Sumatera (Puntius tetrazona) selama penelitian diperoleh analisa keragaman yang disajikan pada table 1 . 
Tabel 1. Hasil ANSIRA terhadap pertambahan berat rata-rata benih ikan sumatera

\begin{tabular}{lllllc}
\hline SK & DB & JK & KT & Fhit & Ftabel \\
\hline Perlakuan & 2 & 0,0017 & 0,0009 & 4,50 & 5,14 \\
Galat & 6 & 0,0011 & 0,0002 & & \\
\hline Total & 8 & 0,003 & & & \\
\hline Keterangan : Berpengaruh tidak nyata & & KK & $: 1,5899$
\end{tabular}

Analisa sidik ragam menunjukkan bahwa pengaruh ketinggian air yang berbeda terhadap pertambahan berat ikan Sumatera (Puntius tetrazona) berpengaruh tidak nyata maka tidak dilakukan uji lanjut. Perbedaan pertambahan berat ikan dapat dilihat pada grafik pertumbuhan berat ratarata benih ikan sumatera (Gambar 1).

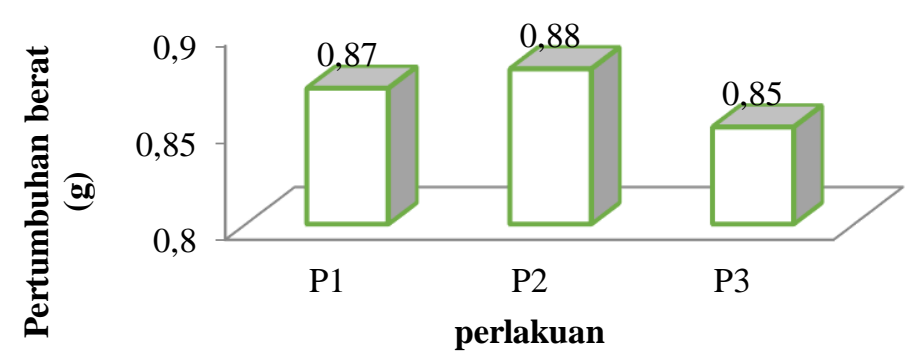

Gambar 1. Rata-rata pertumbuhan berat ikan sumatera

Berdasarkan pada gambar 1 di atas menunjukkan nilai pertambahan berat ratarata tertinggi terdapat pada perlakuan P2 (Ketinggian air $10 \mathrm{~cm}$ ) sebesar 0,88 gram, diikuti dengan perlakuan P1 (Ketinggian air $5 \mathrm{~cm}$ ) yaitu sebesar 0,87 gram, dan perlakuan P3 (Ketinggian Air $15 \mathrm{~cm}$ ) yang terendah yaitu sebesar 0,85 gram. Pada perlakuan P2 (Ketinggian air $10 \mathrm{~cm}$ ) tingkat pertambahan berat tertinggi dari perlakuan lain yaitu dengan berat 0,88 gram. Hal ini diduga pada perlakuan P2 selama masa pemeliharaan jumlah pakan yang diberikan dapat direspon dengan baik oleh benih ikan Sumatera (Puntius tetrazona) dan tidak terdapat sisa-sisa pakan pada media pemeliharaan serta adanya perbedaan ketinggian air dan perbedaan jumlah padat tebar. Menurut Meretsky et al. (2000) dalam Kusmini et al. (2018) mengatakan bahwa perubahan bobot ikan dapat dihasilkan dari perubahan pakan dan alokasi energi untuk tumbuh dan reproduksi, yang mengakibatkan berat ikan berbeda walaupun panjangnya sama. Hal ini diperkuat oleh Jenitasari et al. (2012) menyatakan bahwa kecepatan pertumbuhan tergantung pada jumlah makanan yang diberikan, ruang, suhu, dan dalamnya suatu perairan.

Sedangkan untuk perlakuan P1 (Ketinggian air $5 \mathrm{~cm}$ ) yang pertambahan beratnya lebih rendah dari perlakuan P2 (Ketinggian air $10 \mathrm{~cm}$ ) dan lebih tinggi dari perlakuan P3 (Ketinggian air $15 \mathrm{~cm}$ ) yaitu seberat 0,87 gram. Hal ini diduga rendahnya ketinggian air yang mengakibatkan ruang gerak ikan terbatas dan pakan yang dikonsumsi tidak cukup untuk mendapatkan pertumbuhan optimal. Hal ini diperkuat oleh Hoar et al. (1979) dalam Extrada et al. (2013), menyatakan bahwa hubungan timbal-balik antara setiap individu ikan dengan ikan lainnya dipengaruhi oleh jumlah, ruang, ukuran, dan spesies. Menurut Hickling (1971) dalam Hartini et al. (2013) menyatakan bahwa pertumbuhan juga dipengaruhi oleh kepadatan ikan yang ditebar, dimana dengan padat tebar yang rendah, 
pertumbuhan ikan relatif lebih cepat dan sebaliknya pada padat penebaran yang tinggi pertumbuhan ikan relatif lebih lambat.

Pada perlakuan P3 (Ketinggian Air $15 \mathrm{~cm}$ ) didapatkan hasil pertambahan berat terendah dibandingkan perlakuan P1
(Ketinggian air $5 \mathrm{~cm}$ ) dan P2 (Ketinggian air $10 \mathrm{~cm}$ ) yaitu dengan berat akhir 0,85 gram. Hal ini diduga banyaknya ikan yang ditebar yang mengakibatkan persaingan pakan yang tinggi sehingga mengakibatkan perbedaan pertumbuhan ikan.

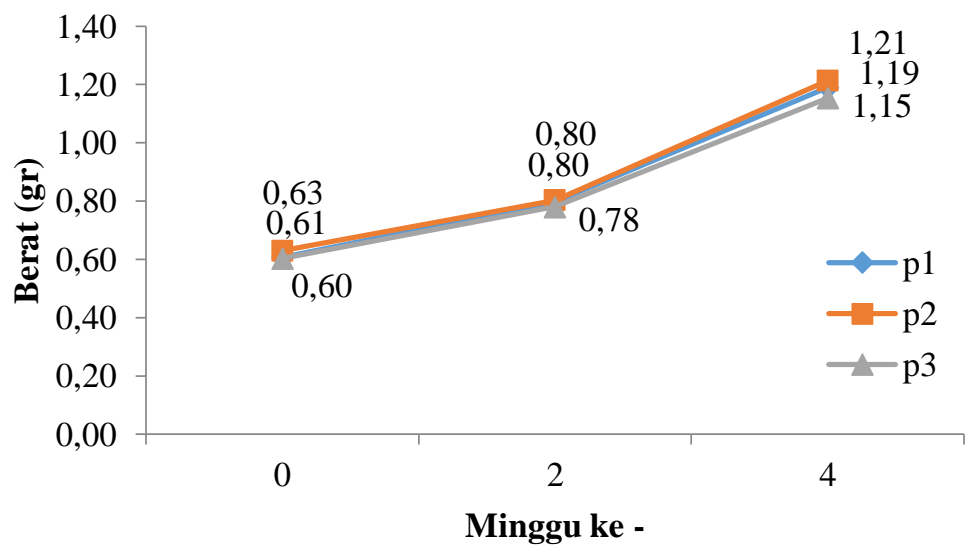

Gambar 2. Rata-rata laju pertambahan berat benih ikan sumatera.

Berdasarkan gambar 2 dapat dilihat bahwa berat rata-rata pada awal penelitian perlakuan P1 sebesar 0,61 gram, perlakuan P2 sebesar 0,63 gram dan perlakuan P3 sebesar 0,60 gram. Selanjutnya pada minggu ke 2 nilai laju pertambahan berat yang didapat pada $\mathrm{P} 1$ sebesar 0,80 gram menunjukkan nilai yang sama dengan P2 sebesar 0,80 gram. Selanjutnya pada minggu ke 4 penelitian nilai laju pertambahan berat tertinggi didapat oleh P2 sebesar (1,21 gram) diikuti dengan P1 sebesar (1,19 gram) dan P3 yang lebih kecil dari P2 dan P1 sebesar (1,15 gram). Hal ini diduga banyaknya ikan yang ditebar yang mengakibatkan persaingan pakan yang tinggi sehingga mengakibatkan perbedaan pertumbuhan ikan. Hal ini diperkuat oleh Hoar et al. (1979) dalam Extrada et al.
(2013) menyatakan bahwa persaingan ruang dan pakan menyebabkan ikan akan mengembangkan pola tingkah laku yang bermacam-macam. Pola tingkah laku tersebut meliputi pertahanan dan dominasi. Hal ini diperkuat oleh penelitian Hermawan et al. (2012), bahwasannya pada padat tebar yang rendah akan menghasilkan bobot individu yang lebih besar dibandingkan dengan padat tebar yang tinggi.

\section{Pertumbuhan Panjang Benih Ikan Sumatera}

Hasil analisa ragam pertumbuhan panjang benih ikan sumatera (Puntius tetrazona) selama penelitian dapat dilihat pada tabel 2.

Tabel 2. Hasil ANSIRA Terhadap pertumbuhan panjang rata-rata benih ikan sumatera

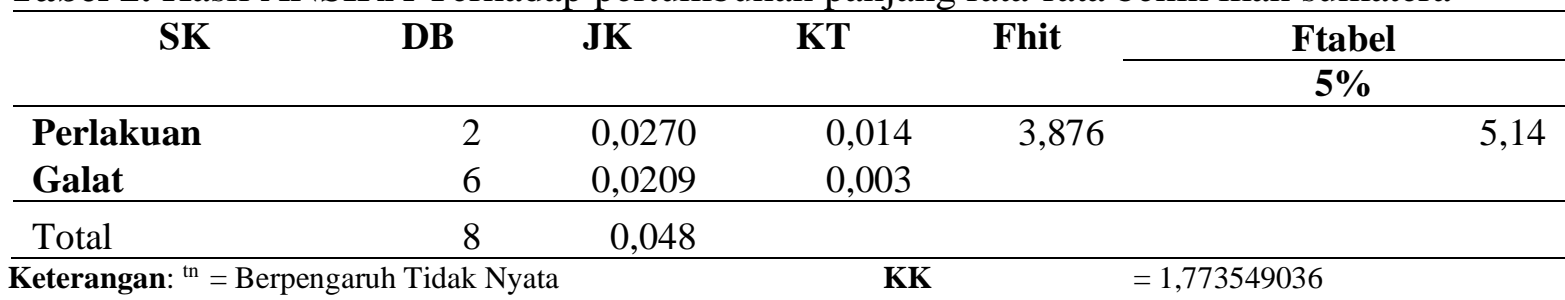


Analisa sidik keragaman menunjukkan bahwa pengaruh ketinggian air yang berbeda terhadap pertumbuhan panjang ikan sumatera (Puntius tetrazona) berpengaruh tidak nyata maka tidak dilakukan uji lanjut. Perbedaan pertumbuhan panjang ikan dapat dilihat pada grafik pertumbuhan berat rata-rata benih ikan sumatera (Gambar 3).

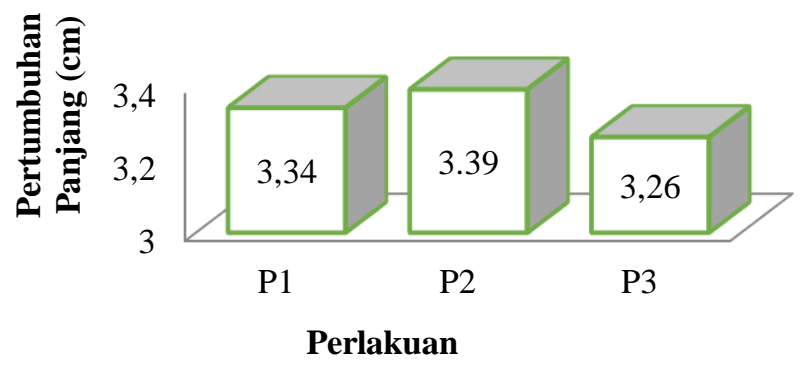

Gambar 3. Rata-rata Pertumbuhan Panjang Ikan Sumatera.

Berdasarkan dari gambar 3 diatas menunjukkan nilai pertumbuhan sampling panjang tertinggi terdapat pada perlakuan P2 (Ketinggian air $10 \mathrm{~cm}$ ) yaitu sebesar $3,39 \mathrm{~cm}$, diikuti perlakuan P1 (Ketinggian air $5 \mathrm{~cm}$ ) sebesar $3,34 \mathrm{~cm}$ dan P3 (Ketinggian air $15 \mathrm{~cm}$ ) sebesar $3,26 \mathrm{~cm}$. Perlakuan P2 (Ketinggian air $10 \mathrm{~cm}$ ) menunjukkan nilai yang tertinggi yaitu $3,39 \mathrm{~cm}$. Hal ini diperkuat Sari et al. (2014) oleh ketinggian air sangat berpengaruh dalam kegiatan pembenihan khususnya pada tahap pemeliharaan larva, dimana tahap ini merupakan tahap yang menentukan berhasil atau tidaknya suatu usaha pembenihan. Menurut Mujiman (1992), laju pertumbuhan dipengaruhi oleh suhu air, persediaan pakan, komposisi makanan, ruang gerak, persediaan oksigen dan hasil buangan metabolisme. Kemudian, hal ini diperkuat oleh Effendi (2004) mengemukakan bahwa pertumbuhan merupakan perubahan bentuk ikan, baik panjang maupun berat sesuai dengan perubahan waktu.

Sedangkan untuk perlakuan P1 (Ketinggian air $5 \mathrm{~cm}$ ) pertumbuhannya yang lebih rendah dibandingkan dengan perlakuan P2 (Ketinggian air $10 \mathrm{~cm}$ ) dan lebih tinggi dari P3 (Ketinggian air $15 \mathrm{~cm}$ ) yaitu sebesar $3,34 \mathrm{~cm}$. Hal ini diduga adanya perbedaan pertumbuhan dan terbatasnya gerak benih ikan Sumatera (Puntius tetrazona) yang menyebabkan ukuran yang berbeda. Hasil pengamatan menunjukkan nilai yang terendah terdapat pada perlakuan P3 (Ketinggian air $15 \mathrm{~cm}$ ) yaitu $3,26 \mathrm{~cm}$. Hal ini diduga adanya perbedaan pertumbuhan dan terbatasnya gerak benih ikan Sumatera (Puntius tetrazona) yang menyebabkan ukuran yang berbeda. Hal ini diperkuat oleh Effendie (1997) yang menyatakan bahwa pertumbuhan ikan sangat ditentukan oleh ketersediaan pakan yang memenuhi kebutuhan nutirisi dan kondisi media pemeliharaan. Selain itu, pertumbuhan ditentukan berdasarkan kualitas induk, kualitas air dan rasio antara jumlah makanan dan kepadatan. Pertumbuhan dipengaruhi oleh 2 faktor yaitu faktor dalam dan faktor luar, adapun faktor dalam yaitu umur, ukuran ikan, dan faktor luar seperti jumlah, ukuran makanan, dan kualitas air (Effendie, 2004). 


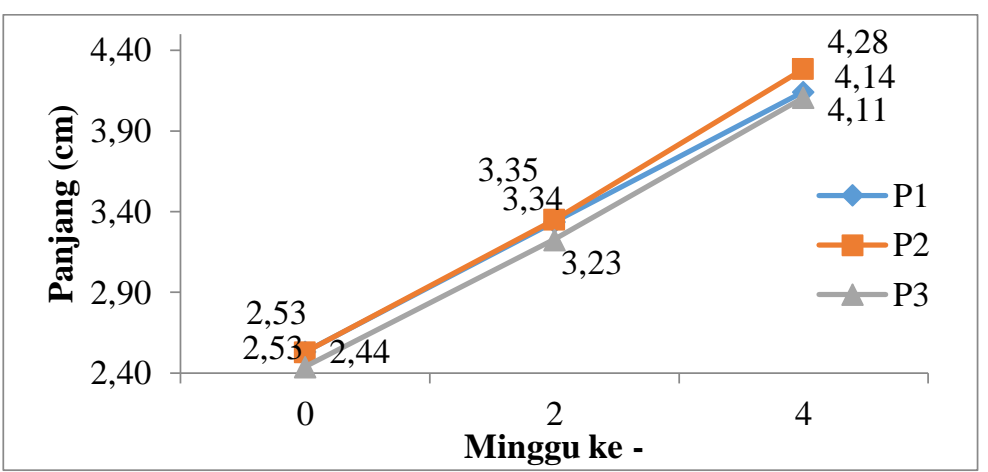

Gambar 4. Grafik Rata-rata Laju Pertumbuhan Panjang Benih Ikan Sumatera.

Berdasarkan gambar 4 dapat dilihat bahwa panjang rata-rata pada awal penelitian perlakuan P1 sebesar 2,53 cm menunjukkan angka yang sama dengan P2 sebesar 2,53 $\mathrm{cm}$ dan lebih tinggi dari P3 sebesar $2,44 \mathrm{~cm}$. Selanjutnya pada minggu ke 2 nilai laju pertumbuhan panjang pada perlakuan P2 sebesar 3,35 $\mathrm{cm}$ dan perlakuan P1 sebesar 3,34 $\mathrm{cm}$ mengalami peningkatan yang tidak berbeda jauh. Pada minggu ke 4 nilai laju pertumbuhan tertinggi didapat pada perlakuan $\mathrm{P} 2$ sebesar 4,28 cm diikuti perlakuan P1 sebesar 4,14 $\mathrm{cm}$, sedangkan nilai yang terendah didapat pada perlakuan $\mathrm{P} 3$ sebesar $4,11 \mathrm{~cm}$.

\section{Kelangsungan Hidup}

Hasil pengamatan terhadap kelangsungan hidup benih ikan Sumatera (Puntius tetrazona) memperoleh analisa keragaman yang disajikan pada tabel 4 .

Tabel 4. Hasil ANSIRA Kelangsungan Hidup Benih Ikan Sumatera

\begin{tabular}{lccccc}
\hline SK & DB & JK & KT & Fhit & Ftabel \\
\hline Perlakuan & 2 & 41,45 & 20,72 & 4,44 & 5,14 \\
Galat & 6 & 28,03 & 4,67 & & \\
\hline Total & 8 & 69,48 & & & \\
Keterangan : $^{\text {tn }}=$ & Berpengaruh Tidak Nyata & KK & $=2,2246$ &
\end{tabular}

Analisa sidik ragam menunjukkan bahwa pengaruh ketinggian air yang berbeda terhadap kelangsungan hidup ikan sumatera (Puntius tetrazona) berpengaruh tidak nyata maka tidak dilakukan uji lanjut. Perbedaan kelangsungan hidup ikan dapat dilihat pada grafik kelangsungan hidup benih ikan sumatera (Gambar 5).

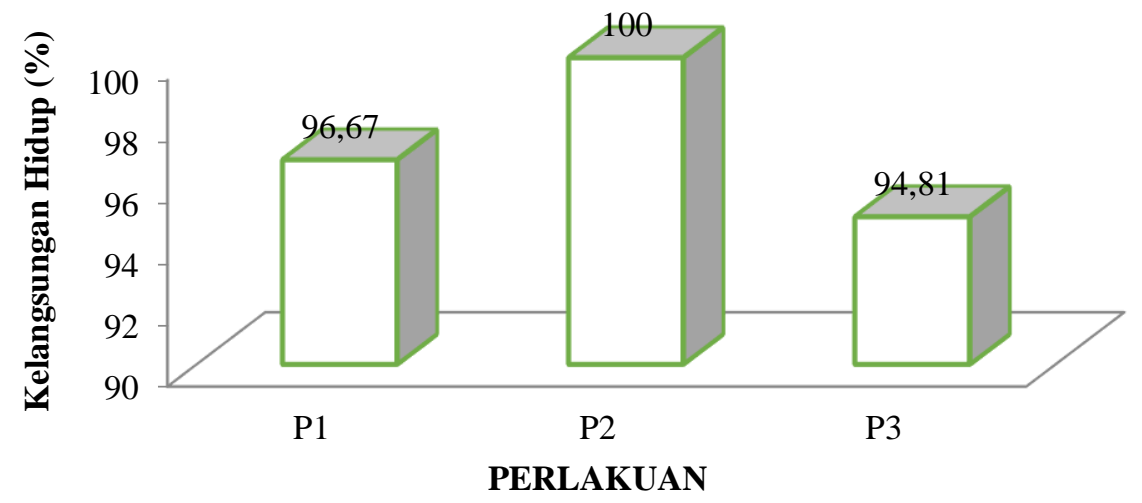

Gambar 5. Grafik Kelangsungan Hidup Benih ikan Sumatera (Puntius tetrazona) 
Dari gambar 5 dapat dilihat perlakuan P1 (Ketinggian air $5 \mathrm{~cm}$ ) yang kelangsungan hidupnya masih kurang dari P2 (Ketinggian air $10 \mathrm{~cm}$ ) dan lebih tinggi dari P3 (Ketinggian air $15 \mathrm{~cm}$ ) yaitu 96,67\%. Hal ini diduga pada perlakuan P1 (Ketinggian air 5cm) memiliki ruang gerak yang terbatas dan ketinggian air yang terbatas sehingga menyebabkan pergerakan ikan menjadi berkurang. Sedangkan untuk Perlakuan P3 (Ketinggian air $15 \mathrm{~cm}$ ) yang kelangsungan hidupnya terendah yaitu sebesar $94,81 \%$. Hal ini diduga efektifitas dalam mencari pakan pada ruang gerak dan ketinggian air pada P2 yang lebih besar dibanding P1. Hal ini diperkuat oleh Odum (1993) dalam Priyadi (2013) yang menyatakan hubungan antara ruang gerak dan ketinggian air pada pemeliharaan larva adalah bahwa ikan pada stadia larva memiliki sifat planktonis sehingga dalam usaha pencarian makannya akan lebih efektif pada ruang dan ketinggian air yang lebih kecil dibandingkan yang besar. Penentuan padat tebar yang tepat merupakan salah satu variabel yang sangat penting dalam bidang budidaya karena akan berpengaruh secara langsung terhadap sintasan, pertumbuhan, tingkah laku, kesehatan, dan kualitas air (Rowland et al., 2006).

\section{Kualitas Air}

Pengamatan kualitas air yang dilakukan selama penelitian meliputi $\mathrm{pH}$, suhu, oksigen terlarut (DO), dan Amonia (NH3) disajikan pada Tabel 5.

Tabel 5. Parameter Kualitas Air Selama Penelitian

\begin{tabular}{lcccc}
\hline \multirow{2}{*}{ Parameter } & \multicolumn{5}{c}{ Perlakuan } & Acuan \\
\cline { 2 - 5 } & P1 & P2 & P3 & SNI \\
\hline $\mathrm{pH}$ & $5-7$ & $5-7$ & $5-7$ & $6,5-8,5$ \\
$\mathrm{DO}(\mathrm{mg} / \mathrm{L})$ & $2,40-3,27$ & $2,45-2,70$ & $2,34-2,90$ & $>5(\mathrm{mg} / \mathrm{l})$ \\
Suhu $\left({ }^{\circ} \mathrm{C}\right)$ & $25,0-29,0$ & $25,0-29,0$ & $25,0-29,0$ & $28^{\circ} \mathrm{C}$ \\
Amonia $(\mathrm{mg} / \mathrm{L})$ & $0,05-0,10$ & $0,05-0,08$ & $0,05-0,11$ & $<0,1$ \\
\hline
\end{tabular}

Berdasarkan Tabel 5 diatas, diperoleh nilai $\mathrm{pH}$ berkisar antara 5 hingga 7 , sedangkan nilai DO berada dibawah nilai standar SNI. Effendi (2003) dalam Ramadhan (2020) mengemukakan bahwa sebagian besar biota akuatik sensitive terhadap perubahan $\mathrm{pH}$ dan menyukai nilai pH sekitar antara 7 hingga 8.5. Rendahnya nilai $\mathrm{pH}$ dan $\mathrm{DO}$ ini di duga karena factor ketinggian air yang menyebabkan ruang gerak ikan yang sempit sehingga oksigen terlarut dalam air rendah. Hal ini diperkuat oleh Pescod (1973) dalam Haris (2019) yang menyatakan bahwa pada $\mathrm{pH}$ rendah (keasaman tinggi) kandungan oksigen terlarut akan berkurang sehingga mengakibatkan konsumsi oksigen menurun, aktivitas pernafasan naik dan selera makan akan berkurang. Nilai suhu masih mendukung untuk pertumbuhan dan kelangsungan hidup ikan. Menurut
Rahmadiah (2013) dalam Wihardi (2014), suhu yang baik untuk budidaya ikan dari family Cyprinidae berkisar $25-30^{\circ} \mathrm{C}$, sedangkan untuk nilai amoniak masih tergolong baik selama penelitian

\section{KESIMPULAN}

Perlakuan P2 (Ketinggian air 10cm) merupakan perlakuan yang terbaik untuk pertumbuhan panjang rata-rata benih Ikan Sumatera (Puntius tetrazona) yaitu $3,39 \mathrm{~cm}$ dan berat yaitu 0,88 gram. Sedangkan tingkat kelangsungan hidup benih Ikan Sumatera (Puntius tetrazona) tertinggi selama penelitian diperoleh hasil P2 (Ketinggian air10cm) yang menunjukkan nilai kelangsungan hidup sebesar $100 \%$. 


\section{DAFTAR PUSTAKA}

Effendie, 1997. Metode Biologi Perikanan. Yayasan Dewi Sri. Bogor, 112 hlm.

Effendie, I. 2004. Pengantar Akuakultur. Penebar Swadaya: Jakarta.

Extrada, E, Ferdinand HT, Yulisman. 2013. Kelangsungan Hidup Dan Pertumbuhan Benih ikan Gabus (Channa striata) Pada Berbagai Tingkat Ketinggian Air Media Pemeliharaan. Jurnal. Akuakultur Rawa Indonesia, 1(1) 103-114 (2013). Program Studi Budidaya Perairan Fakultas Pertanian Universitas Sriwijaya, indralaya,ogan ilir 30662.

Hanafiah, K.A. 2016. Rancangan Percobaan Teori dan Aplikasi. Edisi Ketiga.Cet-16. .Rajawali Pers. Jakarta.hal. 259.

Hartini,S, Susanti.A.D, \& Taqwa, F, H. 2013. Kualitas Air, Kelangsungan Hidup Dan Pertumbuhan Benih Ikan Gabus (Channa striata) Yang Dipelihara Dalam Media Dengan Penambahan Probiotik. Jurnal Akuakultur Rawa Indonesia. Vol.1(2):192-202.

Haris, RBK., Yusanti, I.A. 2019. Analisis Kesesuaian Perairan untuk Keramba Jaring Apung di Kecamatan Sirah Pulau Padang Kabupaten Ogan Komering Ilir Provinsi Sumatera Selatan. Jurnal Lahan Suboptimal. Vol. 8(1) hal: 20-30.

Haris, R.B.K., Kelana, P.P., Basri, M., Nugraha, J.P dan Arumwati. 2020. Perbedaan Ketinggian Air Terhadap Tingkat Pertumbuhan Dan Kelangsungan Hidup Ikan Maskoki (Carassius auratus). Jurnal Ilmu- ilmu Perikanan dan Budidaya Perairan. Vol.15(2) : 113-124.

Hermawan, A.T, Iskandar \& Subhan,U. 2012. Pengaruh Padat Tebar Terhadap Kelangsungan Hidup Pertumbuhan Lele Dumbo(Clarias gariepinus Burch.) Di Kolam Kali Menir Indramayu. Jurnal Perikanan dan Kelautan. ISSN:2088-3137.

Jenitasari, B.A, Sukendi, \& Nuraini.2012. The Effect of Different Natural Food Toward The Growth And Survival Rate Of Tawes Larvae. Universitas Riau. Riau.

Kusmini,I,I., Radona, D\&Putri F,P.2018.Pola Pertumbuhan Dan Faktor Kondisi Benih Ikan Tengadak (Barbonymus schwanenfeldii).Balai Penelitian dan Pengembangan Budidaya Air Tawar. Kalimantan Barat.

Makri, 2015. Sumber Daya Ikan Hias (Puntius tetrazona) Di Danau Ranau Provinsi OKU Selatan Sumatera Selatan. ISBN: 978-60272574-5-0, Jakarta.

Mujiman,A.1992. Feeding Practice. Southern cooperative series. Alabama. 50.

Nafsihi, 2016. Pemanfaatan Tepung Spirulina sp. Untuk Meningkatkan Kecerahan Warna Ikan Sumatera (Puntius tetrazona). Jurnal Rekayasa dan Teknologi Budidaya Perikanan Vol 4 No 2 Februari 2016.

Priyadi, A. Permana, A.dan Nurhidayat.2013. Produksi Massal Benih Ikan Hias Botia (Chromobotia macrocanthus) Melalui Pendekatan Padat Tebar dan Ketinggian Air Media 
Pemeliharaan. Balai Penelitian dan Pengembangan Budidaya Ikan Hias.Depok.

Rafiansyah, 2017. Produksi Ikan Puntius denisonii Ukuran 1 Inchi Pada Padat Tebar Berbeda Dengan Pergantian Air 50\%. Skripsi. IPB University. Bogor.

Ramadhan, R., dan Yusanti, I.A. 2020. Studi Parameter Studi Kadar Nitrat Dan Fosfat Perairan Rawa Banjiran Desa Sedang Kecamatan Suak Tapeh Kabupaten Banyuasin. Jurnal Ilmuilmu Perikanan dan Budidaya Perairan. Vol 15(1) : 37-41. DOI: http://dx.doi.org/10.31851/jipbp.v15 i1.4407.

Rowland, S.J., Mifsuda, C. Nixon,M, \& Boyd,P. 2006. Effect of Stocking density on the performance of the Australia Freshwater Silver Perch (Bidyanus Bidyanus) in cages. Aquaculture, 253:301-308.

Samaun, dkk., 2015. Pengaruh Ketinggian Air yang Berbeda terhadap Pertumbuhan dan Kelangsungan Hidup Benih Ikan Lele Sangkuriang di Balai Benih Ikan Kota Gorontalo. Jurnal Ilmiah Perikanan dan Kelautan. 3 (2).

Sari. 2014. Pengaruh ketinggian air dalam pemeliharaan larva ikan hias botia (Chromobotia macracanthus, Bleeker). Jurnal : Acta Aquatica.1:1 hal 24-30.

Thabrani CN. 2015. Produksi Ikan Sumatra Puntius tetrazona Pada Padat Tebar 5, 10, 15, 20 Ekor/Liter Dalam Sistem Resirkulasi. [Skripsi].Bogor (ID): Institut Pertanian Bogor.

Wihardi. Y., Yusanti, I.A., dan Haris, R.B.K. 2014. Feminisasi pada Ikan Mas (Cyprinus carpio) dengan Perendaman Ekstrak Daun-Tangkai Buah Terung Cepoka (Solanum torvum) pada Lama Waktu Perendaman Berbeda. Jurnal Ilmuilmu Perikanan dan Budidaya Perairan. 9(1) : 23 - 28 .

Yuliansyah, 2017. Pembenihan Ikan Sumatera (Puntius tetrazona) di Balai Penelitian dan Pengembangan Budidaya Ikan Hias Depok. 